\title{
EVALUACIÓN DE LA DIVERSIDAD GENÉTICA DEL CAFÉ (Coffea arabica L.) EN VILLA RICA (PERÚ)
}

\section{EVALUATION OF THE GENETIC DIVERSITY OF THE COFFEE (Coffea arabica L.) IN VILLA RICA (PERU)}

\author{
César Palomino A. ${ }^{1}$, César López B. ${ }^{2}$, Rosa Espejo J. ${ }^{3}$, Roberto Mansilla S. ${ }^{4}$ y Jorge Quispe V. ${ }^{5}$
}

\begin{abstract}
Resumen
El café es el principal producto agrícola de exportación del Perú, con gran importancia económica y social. Un importante centro de producción de este cultivo con un clima particular por su humedad y temperaturas medias máximas y mínimas (en relación a otras zonas productoras de café), altitud (entre 1000 y 1500 m.s.n.m.) y flora nativa, es el Distrito de Villa Rica (Pasco), donde existen diferentes variedades, destacando entre ellas la variedad "Typica". En este estudio se analizó la diversidad genética mediante marcadores RAPD de 42 muestras que corresponden a 18 variedades de café (Coffea arabica L.) y como contraste se utilizó la variedad de café "Robusta" (Coffea canephora Pierre ex Froehner). Se obtuvieron 34 fragmentos de ADN polimórficos; el número de bandas polimórficas por iniciador varió entre uno (utilizando el cebador OPA-17) y cinco (con los cebadores OPA-11 y OPB-05). En el análisis de agrupamiento se construyó un dendograma utilizando el coeficiente de Jaccard y la técnica de ligamento promedio (UPGMA). Este análisis determinó que los cafés arábicos de la zona de Villa Rica presentan un bajo grado de diversidad genética y que no se observa una separación discreta entre las variedades arábicas; sin embargo, la diferenciación genética fue alta con respecto a la variedad Robusta.
\end{abstract}

Palabras clave: Diversidad genética, variedades de café, marcadores moleculares, RAPD, análisis de agrupamiento.

\begin{abstract}
Coffee is the main agricultural export product of Peru, with great economic and social importance. Villa Rica (Pasco) is a major production center due to special climatic conditions of humidity, maximum and minimum average temperatures (in relation to other coffee producing regions), elevation (between 1000 and $1500 \mathrm{~m}$ ) and native flora. Different varieties can be found but "Typica" can be highlighted. Using RAPD markers the genetic diversity of Coffee (Coffea arabica L.) was examined. 42 samples from a total of 18 varieties were used and in contrast a variety of "Robusta" coffee (Coffea canephora Pierre ex Froehner) was employed. Thirty four polymorphic DNA fragments were obtained. The number of polymorphic bands per primer ranged from one (with primer OPA-17) to five (with primers OPA and OPB-11-05). In the cluster analysis a dendrogram was constructed using the Jaccard coefficient and UPGMA technique. This analysis found that Arabica beans from Villa Rica have a low degree of genetic diversity and no discrete separation is observed between Arabica varieties, but genetic differentiation is high with the Robusta variety.
\end{abstract}

Key words: Genetic diversity, coffee varieties, molecular markers, RAPD, cluster analysis.

\section{Introducción.}

El café es el principal producto agrícola de exportación del Perú, alcanzando una gran importancia económica y social ya que ocupa aproximadamente 390.523 mil hectáreas sembradas y proporciona ocupación directa e indirectamente a 180 mil familias (MINAGRI, 2014). Las ventas de grano de café al exterior superaron los US\$ 1337 millones en el 2011 (La Revista Agraria, 2012) y constituyen cerca de un tercio de todo el valor exportado por el sector agrario. En términos de volumen, el Perú es el octavo productor de café en el mundo, pese a que no incluimos esta bebida entre los productos de consumo preferidos (Queirolo, 2010).

En la producción del café se toma en cuenta la procedencia del grano, señalando su origen varietal, las condiciones agroclimáticas en las que se desarrolló el cultivo y el procesamiento durante la cosecha y postcosecha; entre estos factores, el referido a la variedad tiene mucha importancia durante la 
comercialización en algunos países; sin embargo, en el Perú, se comercializa una mezcla de variedades de café arábico que se diferencian por sus características morfológicas y agronómicas; algunas de las más resaltantes se relacionan con la longitud de planta, el color del fruto, la productividad, el rendimiento, la adaptabilidad y resistencia a enfermedades. Al encontrar que estas características son numerosas y muy variables, se podría especular que existen diferencias genéticas entre las variedades de café las cuales son expresadas en el fenotipo; sin embargo, esto sólo se podría afirmar si se determina el grado de diversidad genética que existe entre estas variedades.

Villa Rica es uno de los lugares del Perú que presenta un alto número de variedades cultivadas de café, además abastece de plantones y semillas a otros lugares caficultores, por lo que resulta un espacio importante para un estudio de diversidad genética. Las técnicas moleculares que utilizan marcadores de ADN, como la de RAPD (Random Amplified Polymorphic DNA), gracias a su capacidad de encontrar polimorfismo, resultan ser muy útiles para una primera evaluación de la diversidad. Un estudio de este tipo permitiría hallar las diferencias genéticas que podrían existir entre las variedades de café de la zona de Villa Rica y además sustentaría el grado de diferenciación entre ellas permitiendo entender mejor el aporte del componente genético a la variación fenotípica. Por ello, el objetivo del presente estudio fue estimar el estado de la diversidad genética de las variedades de café en Villa Rica.

\section{Materiales y métodos.}

Material vegetal.

Se colectaron hojas adultas de 42 muestras, que corresponden a 18 variedades de Coffea arabica L. y una variedad de Coffea canephora Pierre ex Froehner. Este material se detalla en la Tabla 1. Las muestras fueron donadas por los propietarios de fundos cafetaleros del Distrito de Villa Rica, Provincia de Oxapampa, Departamento de Pasco. El lugar exacto de los fundos y los nombres de los propietarios se detallan en la Tabla 2. Posteriormente, en el laboratorio de Biología Molecular del Instituto de Biotecnología (IBT), el material vegetal fue conservado a $4^{\circ} \mathrm{C}$ hasta la extracción del ADN.

Extracción del ADN genómico.

Este procedimiento se realizó utilizando un protocolo con buffer CTAB (Bromuro de hexadeciltrimetil amonio) establecido por Doyle \&
Tabla 1. Material vegetal de café colectado en el Distrito de

\begin{tabular}{|c|c|c|c|c|}
\hline $\mathrm{N}^{\mathrm{o}}$ & CÓDIGO & VARIEDAD* & ESPECIE & FUNDO \\
\hline 1 & Typ1 & Typica & C. arabica L. & $\begin{array}{l}\text { San José } \\
\text { Comunidad }\end{array}$ \\
\hline 2 & Тур2 & Typica & C. arabica L. & $\begin{array}{l}\text { Nativa } \\
\text { El Milagro }\end{array}$ \\
\hline 3 & Тур3 & Typica & C. arabica L. & Santa Teresa \\
\hline 4 & Тур4 & Typica & C. arabica L. & Santa Teresa \\
\hline 5 & ТурА & Typica Amarilla & C. arabica L. & Santa Teresa \\
\hline 6 & Bou1 & Bourbon & C. arabica L. & Los Naranjos \\
\hline 7 & Bou2 & Bourbon & C. arabica L. & Santa Teresa \\
\hline 8 & Bou3 & Bourbon & C. arabica L. & El Paraíso \\
\hline 9 & Bou4 & Bourbon & C. arabica L. & Santa Teresa \\
\hline 10 & Bou5 & Bourbon & C. arabica L. & Santa Teresa \\
\hline 11 & Bou6 & Bourbon & C. arabica L. & Santa Teresa \\
\hline 12 & BouA & $\begin{array}{l}\text { Bourbon } \\
\text { Amarillo }\end{array}$ & C. arabica L. & Santa Teresa \\
\hline 13 & BouT & Bourbon Tekisic & C. arabica L. & Santa Teresa \\
\hline 14 & Cat1 & Caturra & C. arabica L. & San Roque \\
\hline 15 & Cat2 & Caturra & C. arabica L. & San Roque \\
\hline 16 & Cat3 & Caturra & C. arabica L. & San José \\
\hline 17 & Cat4 & Caturra & C. arabica L. & ANJA \\
\hline 18 & Cat5 & Caturra & C. arabica L. & Santa Teresa \\
\hline 19 & Cat6 & Caturra & C. arabica L. & Santa Teresa \\
\hline 20 & CatB & Caturra Brasilero & C. arabica L. & Santa Teresa \\
\hline 21 & CatA & Caturra Amarillo & C. arabica L. & Santa Teresa \\
\hline 22 & CatR & Caturra Rojo & C. arabica L. & Santa Teresa \\
\hline 23 & CatVS & $\begin{array}{c}\text { Caturra Villa } \\
\text { Sarchi }\end{array}$ & C. arabica L. & Santa Teresa \\
\hline 24 & Catil & Catimor & $c a \mathrm{~L}$. & San Roque \\
\hline 25 & Cati2 & Catimor & C. arabica L. & San José \\
\hline 26 & Cati3 & Catimor & C. arabica L. & Santa Teresa \\
\hline 27 & Cati4 & Catimor & C. arabica L. & Santa Teresa \\
\hline 28 & Cati5 & Catimor & C. arabica L. & El Paraíso \\
\hline 29 & CatiCR & $\begin{array}{c}\text { Catimor } \\
\text { Costa Rica } 95\end{array}$ & C. arabica L. & Santa Teresa \\
\hline 30 & atiB & $\begin{array}{l}\text { Catimor } \\
\text { Brasilero }\end{array}$ & C. arabica L. & Santa Teresa \\
\hline 31 & Catuai1 & Catuai & C. $c$ & ANJA \\
\hline 32 & Catui2 & Cat & C. arabica L. & Santa Teresa \\
\hline 33 & Catui3 & Catu & C. arabica L. & E1 Paraíso \\
\hline 34 & Pache1 & Pache & C. arabica L. & Los Naranjos \\
\hline 35 & Pache2 & Pache & C. arabica L. & Santa Teresa \\
\hline 36 & Pache3 & Pache & C. arabica L. & E1 Paraíso \\
\hline 37 & Pache4 & Pache & C. arabica L. & Santa Teresa \\
\hline 38 & Pacam & Pacamara & C. arabica L. & Santa Teresa \\
\hline 39 & Marag & Maragogype & C. arabica L. & Santa Teresa \\
\hline 40 & GCol & Gran Colombia & C. arabica L. & Santa Teresa \\
\hline 41 & Mut & Mutante** & C. arabica L. & El Paraíso \\
\hline 42 & Rob & Robusta & C. canephora & Santa Teresa \\
\hline
\end{tabular}

*Denominación que otorga el agricultor. ${ }^{* *}$ Variedad de porte bajo diferente a Caturra.

Doyle (1990), con algunas modificaciones. Este protocolo fue estandarizado en el laboratorio, y utilizado en estudios previos obteniéndose buenos resultados. Al término del proceso de extracción y con el fin de eliminar cualquier interferencia, cada muestra de ADN fue sometida a la acción de la enzima RNAsa (10 $\mathrm{mg} / \mathrm{ml})$. Luego en un espectrofotómetro $\mathrm{UV} /$ visible se cuantificó la concentración de $\mathrm{ADN}$ en 
ng/ $\mu$ l. Además, se evaluó la relación A260/A280 considerada como pureza del ADN.

Análisis RAPD.

El análisis molecular se realizó mediante la técnica RAPD empleando el procedimiento descrito por Williams et al. (1990) el cual incluye algunas modificaciones. Se probaron en total 22 cebadores RAPD de Operon Technologies de los cuales se seleccionaron 10 en base al polimorfismo revelado. El volumen total de reacción de PCR fue de $15 \mu \mathrm{l}$, para ello, se utilizaron $10 \mathrm{ng}$ de $\mathrm{ADN}, 3 \mathrm{U}$ de Taq Polimerasa (BioLabs), $1.4 \mathrm{mM}$ de $\mathrm{MgCl}_{2}, 0.2 \mathrm{mM}$ de dNTPs, $0.25 \mu \mathrm{M}$ de cebador, buffer $10 \mathrm{X}$ y $2 \mathrm{mg}$ de BSA (Albúmina de suero bovino). La reacción se completó con agua MiliQ estéril. Luego se agregó 40

Tabla 2. Ubicación y propietarios de los fundos de Villa Rica.

\begin{tabular}{|c|c|c|c|c|c|}
\hline \multirow[b]{2}{*}{ FUNDO } & \multirow[b]{2}{*}{ SECTOR } & \multirow[b]{2}{*}{ AGRICULTOR } & \multicolumn{3}{|c|}{ UBICACIÓN } \\
\hline & & & $\begin{array}{l}\text { Altitud } \\
\text { (msnm) }\end{array}$ & $\begin{array}{c}\text { Latitud } \\
\text { (sur) }\end{array}$ & $\begin{array}{c}\text { Longitud } \\
\text { (oeste) }\end{array}$ \\
\hline San Roque & $\begin{array}{l}\text { San Miguel } \\
\text { de Eneñas }\end{array}$ & Omar Camargo & 1538 & $10^{\circ} 44.688^{\prime}$ & $75^{\circ} 13.521^{\prime}$ \\
\hline $\begin{array}{c}\text { Los } \\
\text { Naranjos }\end{array}$ & $\begin{array}{l}\text { San Miguel } \\
\text { de Eneñas }\end{array}$ & $\begin{array}{c}\text { Luis de La Cruz } \\
\text { Dávila }\end{array}$ & 1512 & $10^{\circ} 44.847^{\prime}$ & $75^{\circ} 12.858^{\prime}$ \\
\hline San José & $\begin{array}{l}\text { San Miguel } \\
\text { de Eneñas }\end{array}$ & José Talaverano & 1517 & $10^{\circ} 44.862^{\prime}$ & $75^{\circ} 11.834^{\prime}$ \\
\hline $\begin{array}{c}\text { Comunidad } \\
\text { Nativa } \\
\text { El Milagro }\end{array}$ & El Milagro & $\begin{array}{c}\text { Wilmer Abel } \\
\text { Espíritu }\end{array}$ & 1584 & $10^{\circ} 44.166^{\prime}$ & $75^{\circ} 14.820^{\prime}$ \\
\hline ANJA & Yezú & Klaus Valentino & 1523 & $10^{\circ} 43.275^{\prime}$ & $75^{\circ} 15.537^{\prime}$ \\
\hline El Paraíso & Alto Entaz & Domingo Brack & 1517 & $10^{\circ} 46.857^{\prime}$ & $75^{\circ} 16.936^{\prime}$ \\
\hline Santa & Alto & Hans Brack Egg y & 1531 & $10^{\circ} 46.692^{\prime}$ & $75^{\circ} 16.130^{\prime}$ \\
\hline Teresa & $\begin{array}{c}\text { Cedropamp } \\
\mathrm{a}\end{array}$ & Teresa Frantzen & & & \\
\hline
\end{tabular}

$\mu 1$ de aceite mineral a cada reacción antes de colocarlas en un termociclador GeneAmp 9700.

El programa de amplificación utilizado consistió de un primer paso a $94{ }^{\circ} \mathrm{C}$ por cuatro minutos, seguido de 40 ciclos de desnaturalización a $94{ }^{\circ} \mathrm{C}$ por un minuto, alineamiento a $35^{\circ} \mathrm{C}$ por un minuto y una extensión a $72{ }^{\circ} \mathrm{C}$ por dos minutos. Finalmente un paso adicional de extensión a $72{ }^{\circ} \mathrm{C}$ por siete minutos para luego bajar de temperatura a $10{ }^{\circ} \mathrm{C}$. Los productos de PCR fueron separados en gel de agarosa al 1.8 por ciento. La electroforesis tuvo una duración de dos horas utilizando una diferencia de potencial de 100 Voltios. Luego se realizó la tinción de los geles sumergiéndolos en una solución de bromuro de etidio al $0.5 \mathrm{mg} / \mathrm{ml}$ por 30 minutos. Las bandas se visualizaron a través de un equipo Gel Doc 2000 conectado a un ordenador, con el cual se logró registrar las imágenes necesarias para el análisis. El peso molecular de los fragmentos amplificados se estimó utilizando un marcador de peso molecular 100 bp DNA Ladder.

Análisis de los datos.

Los perfiles RAPD obtenidos fueron analizados mediante la observación directa de los patrones en los geles. Es importante precisar que estos perfiles fueron verificados realizando dos amplificaciones diferentes $y$ seguidamente fueron visualizados en gel. Se registró la presencia de banda como 1 y la ausencia como 0 ; de esta manera se logró construir una matriz básica de datos de 42 muestras de café y 34 marcadores RAPD. Utilizando el coeficiente de Jaccard se estimó la similitud para cada par posible de muestras de café y estos datos fueron ordenados en una matriz (Crisci \& López, 1983). Luego se realizó el análisis de agrupamiento (Cluster analysis) con la técnica de

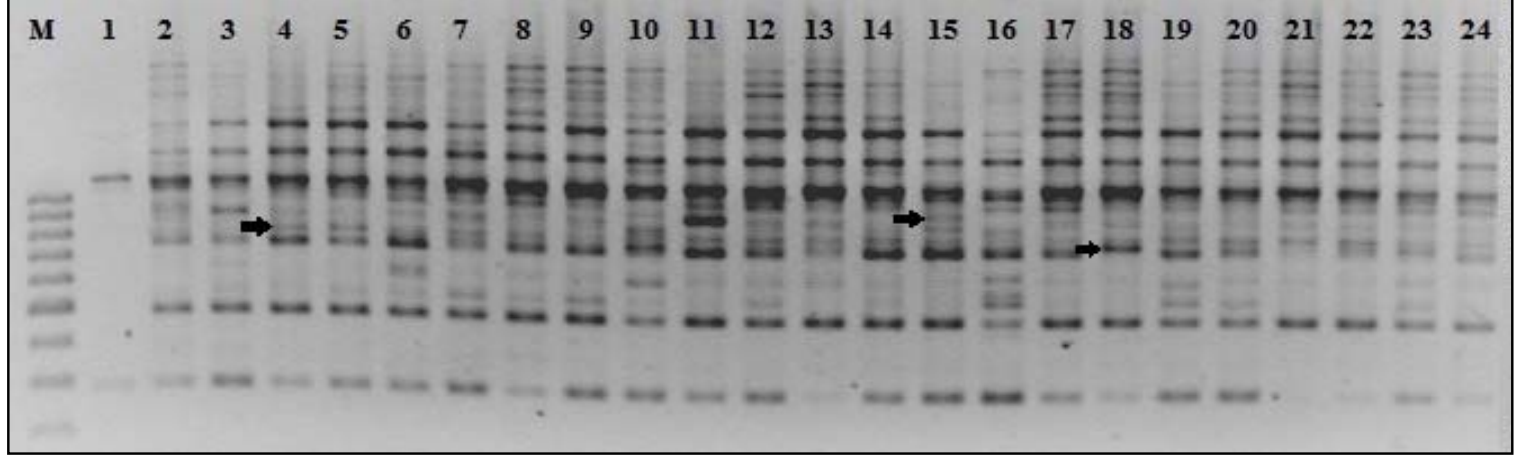

Figura 1. Patrón de bandas RAPD de 24 muestras de café generadas con el cebador OPB- 05.

M (marcador estándar de peso molecular 100 bp DNA Ladder); del 1 al 4 (var. Typica); 5 (Typica Amarilla); del 6 al 11 (Bourbon); 12 (Bourbon Amarillo); 13 (Bourbon Tekisic); del 14 al 19 (Caturra); 20 (Caturra Brasilero); 21 (Caturra Amarillo); 22 (Caturra Rojo); 23 (Caturra Villa Sarchi); 24 (Catimor). Las flechas indican algunas bandas polimórficas. 
ligamento promedio o Unweighted Pair Group Method Using Arithmetic Average (UPGMA) y finalmente se construyó el dendograma respectivo. Para la construcción de la matriz de similitud, el análisis de agrupamiento y la construcción del dendograma se utilizó el programa NTSYSpc2.2.

\section{Resultados.}

En la amplificación de las 42 muestras de café con los cebadores seleccionados se observó que los patrones de amplificación fueron muy conservados en todas las muestras evaluadas, y muy pocos fueron los polimorfismos identificados entre las diferentes variedades de café. Casi todo el polimorfismo se produce entre la variedad Robusta de la especie $C$. canephora y las demás variedades de $C$. arabica. En este estudio se han generado un total de 83 fragmentos de ADN, de los cuales 34 fueron polimórficos y confiables, representando el 40.96 por ciento; además, el número de fragmentos polimórficos por cebador varió entre uno (con el cebador OPA-17) y cinco (con los cebadores OPA-11 y OPB-05), como se observa en la Tabla 3. El tamaño de los fragmentos polimórficos varió entre 316 y 1445 pares de bases. En la Figura 1 se observa el patrón de bandas amplificadas obtenido con el cebador OPB-05, el cual produjo el 50 por ciento de fragmentos polimórficos de un total de 10 fragmentos de $\mathrm{ADN}$.

El dendograma obtenido del análisis de agrupamiento se presenta en la Figura 2. Este resultado confirma la baja diversidad genética entre las variedades de $C$. arabica y concuerda con algunos estudios sobre la diversidad genética entre cultivares comerciales del género Coffea (Lashermes et al., 1993; Orozco-Castillo et al., 1994; Anthony et al., 2001). Para el caso específico del café de Villa Rica, la baja diversidad genética podría atribuirse a la pequeña población fundadora que fue introducida al Perú por los primeros colonos en la selva y que fue multiplicándose y extendiéndose progresivamente. Además, el sistema de reproducción altamente autogámico contribuye a la homogeneidad genética del café de esta zona. Así mismo, en la Figura 2, no se logra observar un agrupamiento entre individuos de la misma variedad ni una separación discreta entre las variedades estudiadas; por ejemplo, todas las muestras de la variedad Typica no se agrupan entre sí; lo mismo ocurre en la variedad Bourbon y otras. Lo que si se aprecia en el dendograma es que hay una mezcla entre los individuos de las diferentes variedades que puede ser explicada por una falta de pureza varietal. Además, los valores de distancia genética son tan bajos que muchos individuos de variedades diferentes presentaron el mismo patrón genético y fueron agrupados en el mismo grupo.

La Figura 2 también permite observar una alta diferenciación genética entre las variedades de $C$. arabica y la variedad Robusta de C. canephora. Estas
Tabla 3. Cebadores RAPD seleccionados y número de fragmentos polimórficos obtenidos en la amplificación del $\mathrm{ADN}$ de café.

\begin{tabular}{cccc}
\hline \multirow{2}{*}{ CEBADORES } & \multicolumn{3}{c}{$\mathrm{N}^{\circ}$ DE FRAGMENTOS } \\
\cline { 2 - 4 } & POLIMÓRFICOS & TOTAL & PORCENTAJE \\
\hline OPA-04 & 3 & 8 & 37.50 \\
OPA-11 & 5 & 9 & 55.55 \\
OPA-15 & 4 & 9 & 44.44 \\
OPA-17 & 1 & 7 & 14.29 \\
OPB-04 & 3 & 9 & 33.33 \\
OPB-05 & 5 & 10 & 50.00 \\
OPR-01 & 3 & 7 & 42.86 \\
OPR-08 & 2 & 5 & 40.00 \\
OPS-03 & 4 & 8 & 50.00 \\
OPS-19 & 4 & 11 & 36.36 \\
TOTAL & 34 & 83 & 40.96 \\
\hline
\end{tabular}

comparten un grado de similitud de solo 12 por ciento, lo cual podría deberse a la poca divergencia de la variedad Robusta, ya que al no ser ésta una especie comercial en el país, no ha sufrido ciclos de selección por parte de los agricultores y por lo tanto, ha mantenido su estructura genética.

\section{Discusión.}

La baja diversidad genética de $C$. arabica se ha atribuido principalmente a la biología reproductiva y al proceso de selección que ha experimentado esta especie. La estrecha base genética del café cultivado, probablemente, es el resultado de la introducción de muy pocas accesiones de países productores como Costa Rica, Brasil, Colombia y que a su vez provinieron del África. Estas accesiones constituyeron la base genética de todos los programas de mejoramiento (Maluf et al., 2005). El resultado de no encontrar una separación evidente entre las variedades de café arábicos de Villa Rica indicaría una posible mezcla de variedades relacionada con la forma de cultivo del café en el Perú; así como el hecho de que una variedad se diferencie de otra en unos pocos caracteres morfológicos. La posibilidad que exista un cruzamiento varietal originando nuevos individuos es muy grande, dado el hecho de que los agricultores, quienes donaron las muestras de café, poseen parcelas que no están separadas por variedades, por lo que en una misma parcela se pueden encontrar varios tipos varietales. Además, este resultado también se puede deber a que la denominación de las variedades, dada por los agricultores, no sea la correcta, concordando esto con un estudio realizado por Blas et al. 2011.

Maluf et al. (2005) obtuvieron un porcentaje de fragmentos polimórficos muy cercano al del presente estudio, en total analizaron 28 variedades de café con 23 cebadores RAPD y de 157 fragmentos amplificados 91 fueron polimórficos, representando el 57.96 por ciento. En este mismo estudio con propósito 
de identificar variedades comerciales de café, estos investigadores utilizaron variedades desarrolladas en el Instituto Agronómico de Campinas (IAC) las que se encuentran cultivadas en todas las áreas cafetaleras de Brasil. Estas variedades al ser mejoradas mediante cruces intervarietales y al estar constituidas por pocos individuos, probablemente presentan una diferencia genética muy parecida a las variedades de café de la zona de Villa Rica, lo que se refleja en un número bajo de fragmentos de ADN polimórficos.

En una investigación realizada por Carvalho et al. (1991) se indica que las variedades de café que derivan del grupo Typica o Bourbon mostraron ser idénticas genéticamente; este resultado puede deberse a que las diferentes variedades fueron derivadas de pocas plantas introducidas de Yemen (Lashermes et al., 1996). A pesar de ello, algunos estudios con marcadores RAPD, como los de Orozco-Castillo et al. (1994) y Lashermes et al. (1996) clasifican la estructura de la diversidad genética del café en tres grupos: cafés de Etiopía, Typica y Bourbon. Las bases genéticas de las variedades Typica y Bourbon se han ido distanciando ligeramente a poco más de tres siglos de selección y sin embargo, están poco diferenciadas del material silvestre de Etiopía. Esto sucede por dos factores: el predominio de la autogamia, lo que favorece la obtención de individuos homocigotos, y la duración del ciclo de selección, lo que limita el número de generaciones. Además, los programas nacionales de semillas desarrollados en los países productores de café han explotado las mutaciones espontáneas que ocurren en las plantaciones, sin ampliar la base genética original (Anthony et al., 2001).

Maluf et al. (2005) obtuvieron un grado de similitud aproximado al 70 por ciento al comparar algunas variedades de $C$. arabica con la variedad Apoatã de C. canephora. Posiblemente el hecho de que este resultado sea mucho mayor al del presente estudio (aproximadamente 12 por ciento), se debe al origen diferente del material estudiado ya que éste procedió de líneas endocriadas. Así mismo, Maluf et al. (2005) utilizaron materiales de C. arabica mejoradas en el IAC, los que probablemente provienen de cruces con variedades de C. canephora o de cruces con variedades híbridas, a diferencia de los materiales que se pueden encontrar en los fundos de Villa Rica, donde no se ha introducido a la especie $C$.

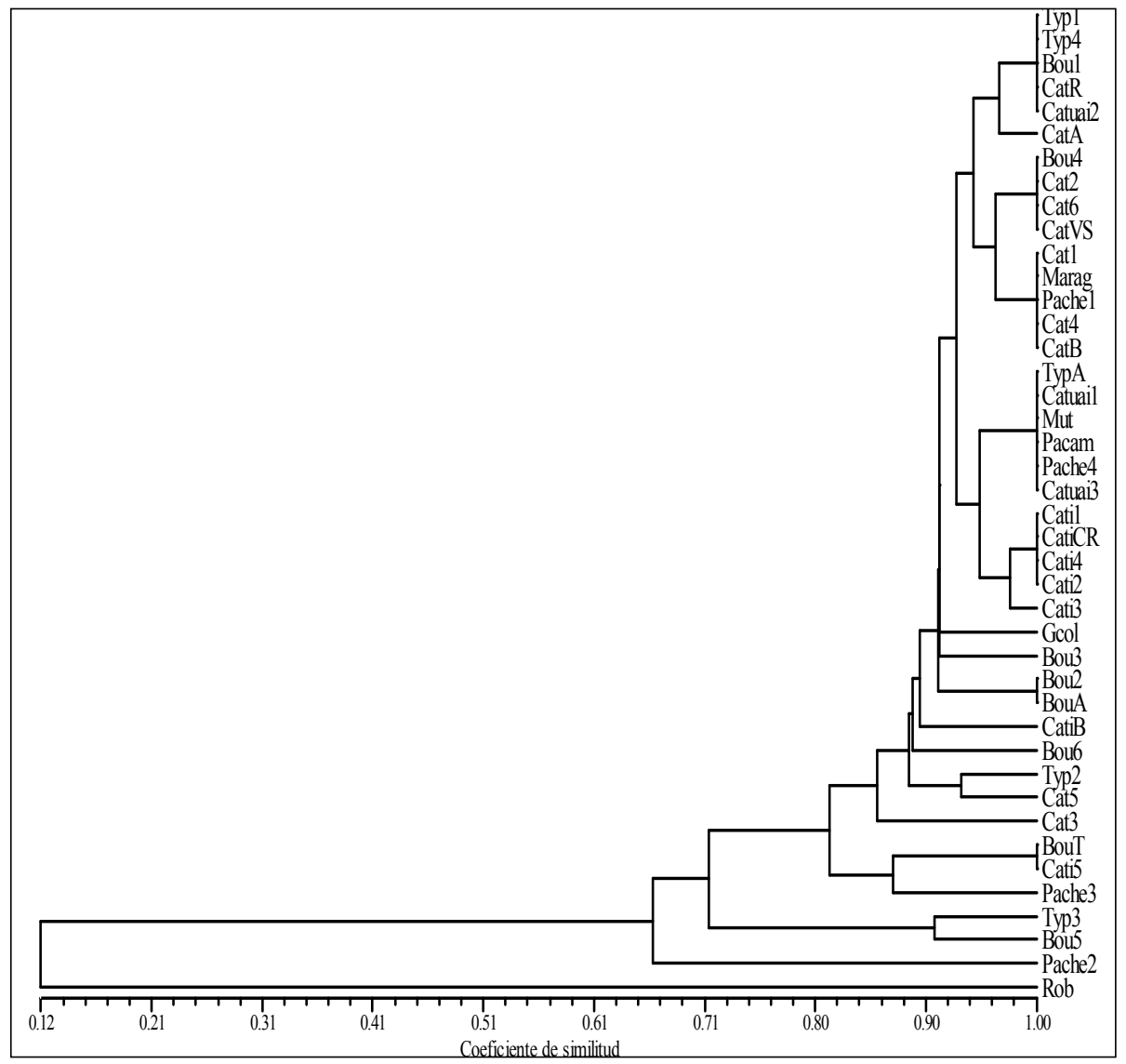

Figura 2. Dendograma que agrupa a las 42 muestras de café evaluadas. 
canephora en grandes cantidades, existiendo muy pocos árboles. Un resultado, más cercano al del presente estudio, fue el obtenido por Steiger et al. (2002) quienes realizaron un análisis de la diversidad genética mediante marcadores AFLP utilizando algunas variedades de C. arabica y una variedad de $C$. canephora, encontrando que éstas comparten un grado de similitud del 54 por ciento. Esto posiblemente se debe a que los materiales utilizados proceden de muestras colectadas en diversos campos de Hawai y no de un banco de germoplasma ex situ que contiene genotipos mejorados como los utilizados en la presente investigación.

\section{Conclusiones.}

Se determinó que el grado de diversidad genética de los cafés arábicos de Villa Rica es bajo debido principalmente a la biología reproductiva autógama y al proceso de establecimiento del cultivo en el Perú y América a través de pocos individuos establecidos en esta zona. Además, se observó una mezcla entre variedades, explicada por la falta de viveros. Sin embargo, también, el término variedad quizá no se aplica totalmente al café por su origen y distribución por las Américas, ya que lo que se tiene son un conjunto de individuos portadores de una que otra mutación seleccionada a los que se les denomina como variedades, aunque la base genética sea muy baja. También, se encontró una alta diferencia genética entre las variedades de C. arabica y la variedad Robusta de $C$. canephora por tratarse de dos especies distintas.

Siendo la zona de Villa Rica un lugar donde existen muchas variedades de café, destacan principalmente la Typica y en menor cantidad la Bourbon, Caturra, Catimor y Pacamara. Finalmente es importante mencionar que los factores climáticos, el manejo en campo y el procesamiento del grano de café influencian grandemente en la obtención de un producto con características especiales por lo que se le ha otorgado el reconocimiento como Denominación de Origen.

\section{Agradecimientos.}

Al proyecto "Denominación de Origen del Café Villa Rica" por el financiamiento de esta investigación y a los señores productores de café de la zona quienes donaron el material vegetal para su uso en este trabajo.

\section{Literatura citada.}

Anthony F., Bertrand B., Quiros O., Lashermes P., Berthaud J. \& Charrier A. 2001. Genetic diversity of wild coffee (Coffea arabica L.) using molecular markers. Euphytica. 118: 53-65.

Carvalho A., Medina Filho H.P., Fazuoli L.C., Guerreiro Filho O. \& Lima M.M. 1991. Aspectos genéticos do cafeeiro. Revista Brasileira de Genética. 14: 135-183.

Crisci J. \& López M. 1983. Introducción a la teoría y práctica de la Taxonomía Numérica. Washington, D.C. Secretaria General de La Organización de los Estados Americanos (OEA)-Programa Regional de Desarrollo Científico y Tecnológico. Serie de biología $\mathrm{N}^{\circ} 26.132 \mathrm{p}$.

Doyle J.J \& Doyle J.L. 1990. Isolation of DNA from small amounts of plant tissues. Focus. 12: 13-15.

La Revista Agraria. 2012. Banano orgánico y café: alta rentabilidad de la pequeña agricultura. Lima, CEPES (Centro Peruano de Estudios Sociales). 138: 12-13.

Lashermes P., Cros J., Marmey Ph. \& Charrier A. 1993. Use of random amplified DNA markers to analysis genetic variability and relationships of Coffea species. Genetic Resources and Crop Evolution. 40: 91-99. , Trouslot P., Anthony F., Combes M.C. \& Charrier A. 1996. Genetic diversity for RAPD markers between cultivated and wild accessions of Coffea arabica. Euphytica. 87: 59-64.

Maluf M.P., Silvestrini M., Machado de Campos L., Guerreiro O. \& Colombo C.A. 2005. Genetic diversity of cultivated Coffea arabica inbred lines assessed by RAPD, AFLP and SSR marker systems. Scientia Agricola. 62(4): 366-373.

MINAGRI. 2014. Frenteweb.minag.gob.pe/sisca

Orozco-Castillo C., Chalmers K., Waugh R. \& Powell W. 1994. Detection of genetic and selective gene introgression in coffe using RAPD markers. Theoretical and Applied Genetics. 87: 934-940.

Queirolo C. 2010. Promoción del consumo interno del café en el Perú: Lineamientos de estrategia. Tesis para optar el grado de Magister en Comunicaciones, Pontificia Universidad Católica del Perú, Escuela de Post-Grado.

Steiger D.L., Nagai C., Moore P.H., Morden C.W., Osgood R.V. \& Ming R. 2002. AFLP analysis of genetic diversity within and among Coffea arabica cultivars. Theoretical and Applied Genetics. 105: 209-215.

Williams J., Kubelik A., Livak K., Rafalski J. \& Tingey S. 1990. DNA polymorphisms amplified by arbitrary primers are useful as genetic markers. Nucleic Acids Research. 18(22): 6531-6535.

1 Instituto de Biotecnología-Universidad Nacional Agraria La Molina. Av. La Molina s/n. Lima-Perú. cepalomino@gmail.com

2 Instituto de Biotecnología-Universidad Nacional Agraria La Molina. Av. La Molina s/n. Lima-Perú. cfeb@lamolina.edu.pe

3 Instituto de Biotecnología-Universidad Nacional Agraria La Molina. Av. La Molina s/n. Lima-Perú. respejo@lamolina.edu.pe

4 Instituto de Biotecnología-Universidad Nacional Agraria La Molina. Av. La Molina s/n. Lima-Perú. rmansilla@lamolina.edu.pe

5 Instituto de Biotecnología-Universidad Nacional Agraria La Molina. Av. La Molina s/n. Lima-Perú. aristeo1310@hotmail.com 